\section{Recruitment of DNA damage recognition and repair pathway proteins following near-IR femtosecond laser irradiation of cells}

\author{
Veronica Gomez-Godinez, ${ }^{a}$ Nicole M. Wakida ${ }^{a}$ \\ Alexander S. Dvornikov, ${ }^{a}$ Kyoko Yokomori, ${ }^{b}$ and \\ Michael W. Berns ${ }^{\mathrm{a}, *}$ \\ aUniversity of California-Irvine \\ Beckman Laser Institute \\ Irvine, California 92612 \\ ${ }^{b}$ University of California-Irvine \\ Department of Biological Chemistry, School of Medicine \\ Irvine, California 92697
}

\begin{abstract}
An 800-nm 200-fs laser is used to produce DNA damage in rat kangaroo (PtK1) and human cystic fibrosis pancreatic adenoma carcinoma (CFPAC-1) cells. Immunofluorescence staining for DNA repair factors in irradiated cells displays localization of $\gamma \mathrm{H} 2 \mathrm{AX}, \mathrm{Nbs} 1$, and Rad50 to the site of irradiation 3 to 30 min following laser exposure. It is concluded that the 200-fs near-infrared laser is an excellent source for the production and study of spatially defined regions of DNA damage. ( 2007 Society of Photo-Optical Instrumentation Engineers. [DOI: 10.1117/1.2717684]
\end{abstract}

Keywords: DNA damage; femtosecond laser; laser microsurgery.

Paper 06369LR received Dec. 14, 2006; revised manuscript received Jan. 25, 2007; accepted for publication Jan. 30, 2007; published online Mar. 29, 2007.

\section{Introduction}

The laser microbeam is being used by many laboratories around the world to study DNA damage and repair. These studies generally involve the production of a spatially defined alteration in the cell nucleus, followed by antibody staining for specific DNA repair factors. In these studies, several different lasers and ablation parameters are used: 1. 337-nm UVA wavelength from the $\mathrm{N}_{2}$ laser in combination with a DNA-binding sensitizing agent such as BrdU, ${ }^{1}$ 2. the 337-nm wavelength of the $\mathrm{N}_{2}$ laser used either with BrdU alone or with BrdU and Hoescht at the same time, ${ }^{2}$ 3. the 337-nm $\mathrm{N}_{2}$ laser used alone, ${ }^{1} 4$. the $532 \mathrm{~nm}$ of the Q-switched nanosecond laser, ${ }^{3} 5$. the 532-nm picosecond laser, ${ }^{4}$ and 6 . the 364-nm wavelength of the cw argon ion laser. ${ }^{5}$ In all of these studies, the spatially defined areas of laser irradiation in the nucleus were shown to contain either damage recognition proteins, checkpoint proteins, or DNA repair proteins at varying time points following exposure to the focused laser beam.

In this study we utilized a 200-fs near-infrared $(800 \mathrm{~nm})$ laser to induce damage in the subnuclear region. We used known markers for DNA double strand breaks (DSBs), in-

*Tel: 714/824-7565; E-mail: mwberns@uci.edu cluding phosphorylation of the histone $\mathrm{H} 2 \mathrm{~A}$ variant $\mathrm{H} 2 \mathrm{AX}$ and recruitment of $\mathrm{Nbs} 1$ and $\operatorname{Rad} 50$ (components of the trimeric Mre11 complex), to assess the presence of DNA damage and cellular response at the laser-induced damage sites. Phosphorylation of $\mathrm{H} 2 \mathrm{AX}$ at serine 139 (termed " $\gamma \mathrm{H} 2 \mathrm{AX}$ ") occurs specifically at the DSB damage site and surrounding areas as part of DSB-induced checkpoint signaling. ${ }^{2,6}$ The Mre11 complex is one of the earliest DSB factors to be recruited to the damage site and is involved in both DSB checkpoint signaling and repair. ${ }^{7,8}$ Our results demonstrated that damage generated by exposure to the ultra-short femtosecond laser pulses at and below the resolution of the optical microscope induces DSB checkpoint response and is recognized by DSB repair factors, indicating that the system can be used to study cellular DNA damage response and repair.

\section{Materials and Methods}

\subsection{Cell Culture}

Rat kangaroo, Potorous tridactylus, kidney epithelial cells (PTK1, American Type Culture Collection, [ATCC] CCL 35) and human cystic fibrosis pancreatic adenocarcinoma (CFPAC-1, ATCC CRL 6493) cells were grown in Gibco advanced Dulbeccio's Modified Eagle Medium (DMEM) F-12 supplemented with L-glutamine, and $3 \%$ fetal bovine serum. The cells were incubated at $37^{\circ} \mathrm{C}$ with $5 \% \mathrm{CO}_{2}$. Cells were seeded into Rose chambers at a density of $3.3 \times 10^{5}$ cells per $\mathrm{mL}$ and allowed to grow for 24 to $48 \mathrm{~h}$ until semiconfluency, at which time they were used for experimentation at a density of 1 to $1.4 \times 10^{6}$ cells per $\mathrm{mL}$ in Rose chambers, as was previously described. ${ }^{9}$

\subsection{Laser Irradiation}

Irradiation was performed with a Verdi-pumped Mira titanium sapphire laser (Coherent Incorporated, Santa Clara, California) emitting 200-fs $800-\mathrm{nm}$ pulses at $76 \mathrm{MHz}$. Individual laser exposure in the cell nucleus was for $20 \mathrm{~ms}$ at either $2.1 \times 10^{6}$ or $6.1 \times 10^{6} \mathrm{~W} / \mathrm{cm}^{2}$ using the laser and imaging setup as previously described. ${ }^{10}$

\subsection{Immunofluorescent Staining}

Cells were washed with phosphate buffered saline (PBS) and fixed by $4 \%$ paraformaldehyde for $15 \mathrm{~min} 3$ to $36 \mathrm{~min}$ following laser exposure. Cells were permeabilized overnight with $0.1 \%$ TritonX in PBS blocking buffer containing $2.5 \%$ FBS. After permeabilization, cells were stained for immunofluorescence with antibodies for three DNA repair/recruitment factors: $\gamma \mathrm{H} 2 \mathrm{AX}$ (Upstate Biotechnology, Temecula, California), a phosphorylated histone that is a DNA-damage marker and two DNA repair factors, Nbs1 (Novus Biologicals, Littleton, Colorado), and Rad50 (GeneTex, San Antonio, California). Zymax Cy3 goat antirabbit and FITC goat antimouse IgG antibodies (Zymed Laboratories, San Francisco, California) were used to detect the primary antibodies, as previously described. ${ }^{11}$

\subsection{Imaging}

Cells were refound by using postirradiation images and grid coordinates. Fluorescence imaging was performed as previ-

$1083-3668 / 2007 / 12(2) / 020505 / 3 / \$ 25.00$ ○ 2007 SPIE 


\section{JBO LETTERS}
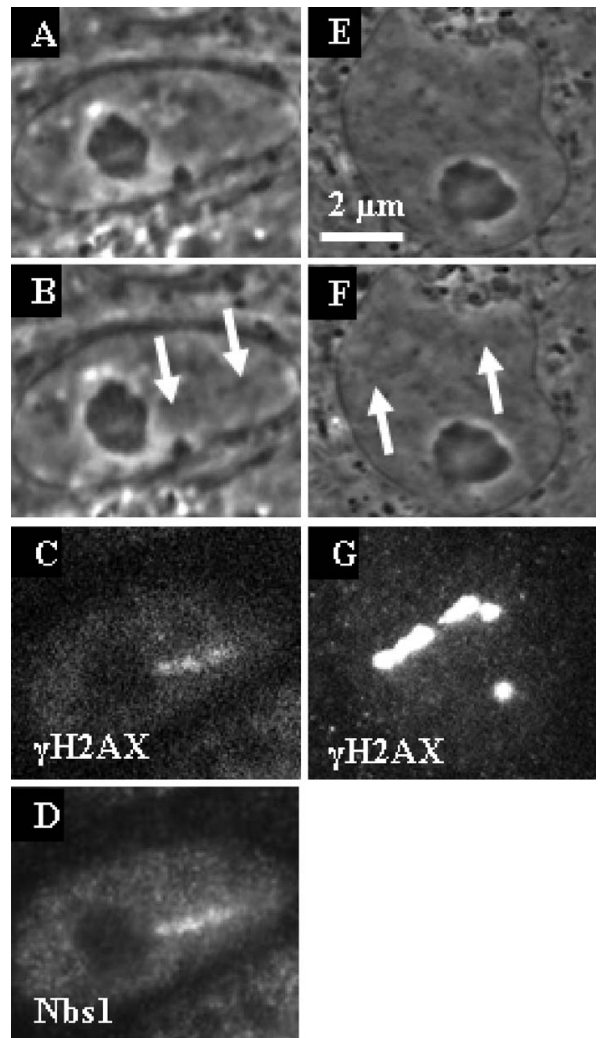

Fig. 1 (a) through (d) CFPAC-1 and (c) through (g) PTK1 cells irradiated at $2.1 \times 10^{6} \mathrm{~W} / \mathrm{cm}^{2}$ show no damage at exposure site. However, immunofluorescent staining of cells fixed three minutes after irradiation show localization of repair factors to damage site.

ously described..$^{10}$ The width of the line at the site of irradiation was measured by counting pixels of postirradiation images using Image $\mathbf{J}$.

\section{Results}

\subsection{Low Irradiance $\left(2.1 \times 10^{6} \mathrm{~W} / \mathrm{cm}^{2}\right)$}

CFPAC-1 and PTK2 cells irradiated at $2.1 \times 10^{6} \mathrm{~W} / \mathrm{cm}^{2}$ did not appear damaged when viewed with the light microscope [Figs. 1(a), 1(b), 1(e), and 1(f)]. However, following staining with the $\gamma \mathrm{H} 2 \mathrm{AX}$ and Nbs1 antibodies, a distinct line of fluorescence was detected that matched the laser exposure region in eight out of eight cells [Figs. 1(c), 1(d), and 1(g)]. Fluorescence corresponding to the site of irradiation was detected in cells fixed as early as three minutes after irradiation.

\subsection{High Irradiance $\left(6.1 \times 10^{6} \mathrm{~W} / \mathrm{cm}^{2}\right)$}

Cells irradiated at $6.1 \times 10^{6} \mathrm{~W} / \mathrm{cm}^{2}$ and stained for Nbs1 and Rad50 (Fig. 2) repair factors show strong fluorescence confined to the site of irradiation in 22 out of 23 cells and 12 out of 14 cells, respectively. Of particular interest is the $300-\mathrm{nm}$ diam narrow phase-dark line of damage [Figs. 2(b) and 2(f)]. Both repair factors appear to be localized in the same damage zone. Cells irradiated at this irradiance and antibody stained for $\gamma \mathrm{H} 2 \mathrm{AX}$ exhibited bright fluorescence throughout the entire nucleus, making it difficult to discriminate the primary damage site as was evidenced at the lower irradiance presented in Fig. 1.
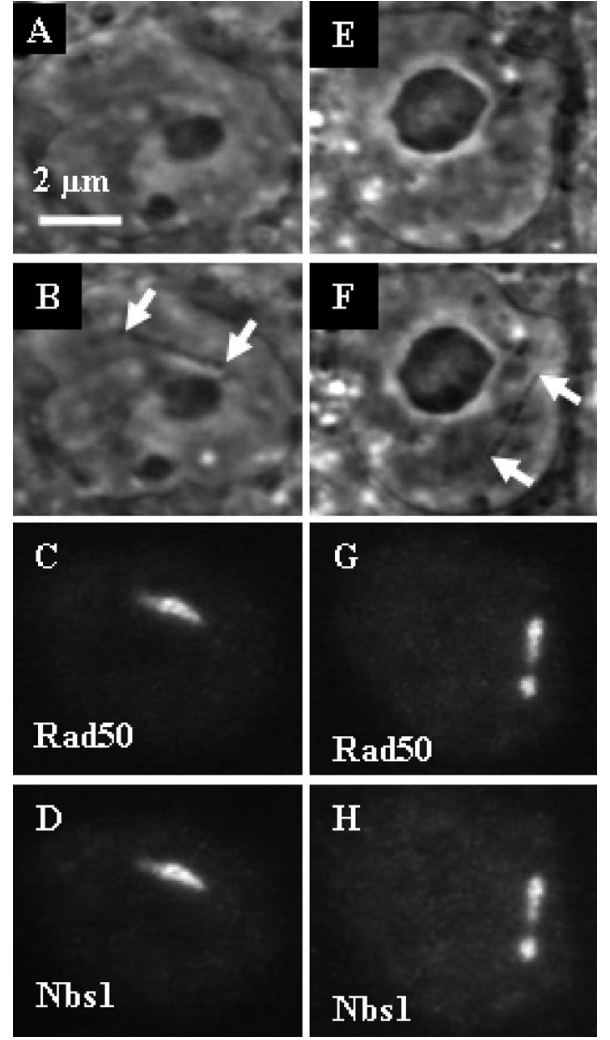

Fig. 2 (b) through (e) CFPAC-1 cells irradiated at $6.1 \times 10^{6} \mathrm{~W} / \mathrm{cm}^{2}$ show a narrow phase-dark line of damage. Both Rad50 and Nbs1 localized to the site of damage.

\section{Discussion}

The localization of $\gamma \mathrm{H} 2 \mathrm{AX}, \operatorname{Rad} 50$, and Nbs1 to the site of laser irradiation demonstrates that the femtosecond near-IR laser can induce spatially confined DNA/chromatin damage. This damage is probably due to multiphoton and plasmainduced mechanisms of ablation. Resulting damage is nonspecific to the type of molecules, but results in the ablation of molecules within the focal spot of the laser, thus causing multiple DSB surrounding the site of laser exposure. Due to the presence of known DSB markers (gamma H2AX and the Mre11 complex) at the damage sites, laser exposure certainly resulted in DSBs. These results are comparable to those obtained with UV BrdU sensitization ${ }^{1,2,12}$ and with the different 532-nm laser systems. ${ }^{3,4}$ Our observation of early induction of $\gamma \mathrm{H} 2 \mathrm{AX}$ in the nucleus of irradiated cells is consistent with previous findings that $\gamma \mathrm{H} 2 \mathrm{AX}$ gets phosphorylated as early as one to three minutes after exposure to ionizing radiation. ${ }^{2}$ Additionally, our finding that increasing the laser dose from $2.1 \times 10^{6}$ to $6.1 \times 10^{6} \mathrm{~W} / \mathrm{cm}^{2}$ in the focal spot resulted in spreading of $\gamma \mathrm{H} 2 \mathrm{AX}$ beyond the region of laser exposure is consistent with previous findings that larger doses of ionizing radiation and UVA laser power resulted in increased H2AX phosphorylation. ${ }^{1,2}$ However, the mechanism whereby the damage is conferred to most of the nucleus when only a small region of the nucleus is exposed is not known. Of particular interest is the observation that when the laser dose was reduced to $2.1 \times 10^{6} \mathrm{~W} / \mathrm{cm}^{2}$ in the focal spot, little or no damage was detected at the light microscope level, but antibody staining was detected at the irradiation site that matched the 
spatial pattern of laser exposure in the live cell. This demonstrates that the 200-fs laser can produce site-specific damage to the DNA.

Immunofluorescence antibody staining for $\mathrm{Nbs} 1$ and Rad50 shows specific localization to the site of irradiation similar to that seen in previous studies involving laser microsurgery using both UV and 532-nm Nd: YAG lasers. ${ }^{1-3,5,12-14}$ In all cases, the fluorescence is very strong at the site of laser exposure. Studies have shown that Nbs1 localized to the sites of damage as early as $30 \mathrm{~s}$ after irradiation in human cells. ${ }^{14}$ Our findings of early localization are consistent with those results. However, of particular interest in our study is the production of a very thin line of damage as seen in the phasecontrast images [Fig. 2(b)]. This 300-nm-diam line of damage is just at the resolution of the light microscope and compares well with the 100- to 200-nm damage zone in chromosomes that were irradiated with a femtosecond laser and subsequently examined by scanning electron microscopy. ${ }^{15}$ However, those studies were conducted on dried chromosomes removed from cells, and the studies we report here were conducted on live cells. It is most likely that in those studies, as well as the ones reported here, the damage was caused by multiphoton absorption in the tightly focused spot. Such events were described in laser-irradiated chromosomes more than 25 years ago using a pulsed 10-ns 532-nm Nd:YAG laser. ${ }^{16,17}$ More recently, multiphoton-induced gene inactivation has been described following irradiation of the ribosomal gene sites on late prophase chromosomes using a 100-ps $\mathrm{Nd}$ : YAG laser operating at a wavelength of $1.06 \mu \mathrm{m} .{ }^{18}$ In that study, the chromosomes were sensitized with the nontoxic vital stain ethidium bromide, which had a peak absorption at $530 \mathrm{~nm}$, very close to the two-photon absorption wavelength of the $1.06-\mu \mathrm{m}$ laser.

In summary, we show that DNA/chromatin damage followed by $\gamma \mathrm{H} 2 \mathrm{AX}$ phosphorylation and double-strand break repair factor recruitment can be induced by a 200 -fs nearinfrared 800-nm laser. Live cells display spatially defined damage zones as thin as $300 \mathrm{~nm}$ within $30 \mathrm{~s}$ of laser exposure. These damage regions stain with antibodies for DNA recruitment and repair factors. Irradiation with laser irradiance below the threshold for visible damage in live cells detected by phase-contrast light microscopy reveals antibody staining confined to the exact sites of laser exposure. The general transparency of the cell to the near-IR femtosecond laser, plus the confinement of cell damage only to the focal point where the multiphoton and other nonlinear physical events may occur, make this laser ideal for future studies on DNA damage and repair mechanisms.

Note added in proof: Recently, a similar femtosecond laser was used to study non-homologous end-joining factors [Marc et al., Proc. Nat. Acad. Sci. USA 103, 18597-18602].

\section{Acknowledgments}

This work was supported by grants from the United States Air Force (AFOSR F9620-00-1-0371), the National Institute of Health (NIH RR 14892), and the Department of Defense Breast Cancer Research Program (DAMD17-03-1-0436 to
Yokomori). A special thanks to the Arnold and Mabel Beckman Foundation and to Minorities Access to Research Careers (NIH GM 69337).

\section{References}

1. C. Lukas, J. Falck, J. Bartkova, J. Bartek, and J. Lukas, "Distinct spatiotemporal dynamics of mammalian checkpoint regulators induced by DNA damage," Nat. Cell Biol. 5(3), 255-260 (2003).

2. E. P. Rogakou, C. Boon, C. Redon, and W. M. Bonner, "Megabase chromatin domains involved in DNA double-strand breaks in vivo," J. Cell Biol. 146(5), 905-916 (1999).

3. J. S. Kim, T. B. Krasieva, V. LaMorte, A. M. Taylor, and K. Yokomori, "Specific recruitment of human cohesin to laser-induced DNA damage," J. Biol. Chem. 277(47), 45149-45153 (2002).

4. B. P. Chen, D. W. Chan, J. Kobayashi, S. Burma, A. Asaithamby, K. Morotomi-Yano, E. Botvinick, J. Qin, and D. J. Chen, "Cell cycle dependence of DNA-dependent protein kinase phosphorylation in response to DNA double strand breaks," J. Biol. Chem. 280(15), 14709-14715 (2005).

5. K. Negishi, S. Higashi, T. Nakamura, C. Otsuka, M. Watanabe, and T. Negishi, "Oxidative DNA damage induced by 364-nm UVA laser in yeast cell," Genes Environ. 28(2), 74-76 (2006).

6. E. P. Rogakou, D. R. Pilch, A. H. Orr, V. S. Ivanova, and W. M. Bonner, "DNA double-stranded breaks induce histone H2AX phosphorylation on serine 139," J. Biol. Chem. 273(10), 5858-5868 (1998).

7. M. F. Lavin, "The Mre11 complex and ATM: a two-way functional interaction in recognising and signaling DNA double strand breaks," DNA Repair 3(11), 1515-1520 (2004).

8. B. E. Nelms, R. S. Maser, J. F. MacKay, M. G. Lagally, and J. H. Petrini, "In situ visualization of DNA double-strand break repair in human fibroblasts," Science 280(5363), 590-592 (1998).

9. M. W. Berns, E. Botvinick, L. Liaw, C. Sun, and J. Shah, in Cell Biology a Laboratory Handbook, J. E. Celis, Ed., Chap. 36, pp. 352 353, Copenhagen (2006).

10. N. M. Wakida, C. S. Lee, E. L. Botvinick, L. Z. Shi, A. Dvornikov, and M. W. Berns, "Laser nanosurgery of single microtubules reveals location dependent depolymerization rates," J. Biomed. Opt. 12(2), 024027 (2007).

11. T. T. Paull, E. P. Rogakou, V. Yamazaki, C. U. Kirchgessner, M. Gellert, and W. M. Bonner, "A critical role for histone H2AX in recruitment of repair factors to nuclear foci after DNA damage," Curr. Biol. 10(15), 886-895 (2000).

12. S. Bekker-Jensen, C. Lukas, R. Kitagawa, F. Melander, M. B. Kastan, J. Bartek, and J. Lukas, "Spatial organization of the mammalian genome surveillance machinery in response to DNA strand breaks," $J$. Cell Biol. 173(2), 195-206 (2006).

13. L. Lan, S. Nakajima, Y. Oohata, M. Takao, S. Okano, M. Masutani, S. H. Wilson, and A. Yasui, "In situ analysis of repair processes for oxidative DNA damage in mammalian cells," Proc. Natl. Acad. Sci. U.S.A. 101(38), 13738-13743 (2004).

14. C. Lukas, F. Melander, M. Stucki, J. Falck, S. Bekker-Jensen, M. Goldberg, Y. Lerenthal, S. P. Jackson, J. Bartek, and J. Lukas, "Mdc1 couples DNA double-strand break recognition by Nbs1 with its H2AX-dependent chromatin retention," EMBO J. 23(13), 2674-2683 (2004).

15. K. Konig, I. Riemann, and W. Fritzsche, "Nanodissection of human chromosomes with near-infrared femtosecond laser pulses," Opt. Lett. 26(11), 819-821 (2001).

16. M. W. Berns, J. Aist, J. Edwards, K. Strahs, J. Girton, P. McNeill, J. B. Rattner, M. Kitzes, M. Hammer-Wilson, L. H. Liaw, A. Siemens, M. Koonce, S. Peterson, S. Brenner, J. Burt, R. Walter, P. J. Bryant, D. van Dyk, J. Coulombe, T. Cahill, and G. S. Berns, "Laser microsurgery in cell and developmental biology," Science 213(4507), 505513 (1981).

17. P. P. Calmettes and M. W. Berns, "Laser-induced multiphoton processes in living cells," Proc. Natl. Acad. Sci. U.S.A. 80(23), 71977199 (1983)

18. M. W. Berns, Z. Wang, A. Dunn, V. Wallace, and V. Venugopalan, "Gene inactivation by multiphoton-targeted photochemistry," Proc. Natl. Acad. Sci. U.S.A. 97(17), 9504-9507 (2000). 